\title{
Signaling via the CXCR5/ERK pathway is mediated by CXCL13 in mice with breast cancer
}

\author{
LICHENG XU ${ }^{1}$, ZHI LIANG ${ }^{1}$, SHUYAN LI $^{1}$ and JIANJUN MA ${ }^{2}$ \\ ${ }^{1}$ Department of Breast Surgery, Yantaishan Hospital; ${ }^{2}$ Department of Medical Oncology, \\ The People's Liberation Army 107th Hospital, Yantai, Shandong 264002, P.R. China
}

Received January 20, 2017; Accepted January 10, 2018

DOI: $10.3892 / \mathrm{ol} .2018 .8510$

\begin{abstract}
Breast cancer is the most common cause of cancer-associated mortality and the most frequently diagnosed type of cancer in women worldwide. It has been revealed that the chemokine $\mathrm{C}-\mathrm{X}-\mathrm{C}$ motif chemokine ligand 13 (CXCL13) serves a pivotal role in breast cancer growth and is associated with lymph node metastasis. However, to the best of our knowledge, the mechanism by which CXCL13 mediates breast cancer growth remains uncharacterized. Female BALB/c mice were used in this study. Tumor volume was calculated and changes of gross tumor morphology were observed by hematoxylin and eosin staining. The expression of CXCL13, C-X-C motif chemokine receptor 5 (CXCR5) and extracellular signaling-related kinase (ERK) mRNA and protein expression were detected by reverse transcriptase quantitative-polymerase chain reaction and western blot analysis. Simultaneously, the production of cytokines [interleukin-1 $\beta$ (IL-1 $\beta$ ), tumor necrosis factor (TNF) and tumor growth factor $\beta 1$ (TGF- $\beta 1)$ ] was detected by an ELISA. The CXCL13 inhibitor reduced tumor volume and growth, and reduced the mRNA and protein expression levels of key members of the CXCR5/ERK signaling pathway: CXCL13, CXCR5 and ERK. Furthermore, the detectable concentration of the cytokines IL-1 $\beta$ and TNF decreased following CXCL13 inhibition, whereas the concentration of TGF- $\beta 1$ was increased. The attenuation of tumor growth resulting from CXCL13 inhibition may be associated with the CXCR5/ERK signaling pathway. This study provides a theoretical basis for treating breast cancer through CXCL13 inhibition in clinical trials.
\end{abstract}

Correspondence to: Dr Jianjun Ma, Department of Medical Oncology, The People's Liberation Army 107th Hospital, 7 Zhichunan Road, Yantai, Shandong 264002, P.R. China E-mail: jianjunma1@163.com

Key words: chemokine, C-X-C motif chemokine ligand 13, C-X-C motif chemokine receptor 5 , extracellular-related signaling kinase, breast cancer

\section{Introduction}

Breast cancer is the leading cause of cancer-associated mortality among females, and is responsible for $23 \%$ of the total cases of cancer and $14 \%$ of cancer-associated mortalities globally (1-3). Multiple chemokines are secreted by cancer cells, and the host cannot regulate this process autonomously $(4,5)$. Chemokines and their receptors make up the chemokine family, with the ligand or receptor proteins are indicated by the letter $\mathrm{L}$ or $\mathrm{R}$, respectively (6). C-X-C motif chemokine ligand 13 (CXCL13), also known as B-lymphocyte chemoattractant, was originally identified in stromal cells in B-cell follicles as regulating subsets of T cells and the homing of B cells (7). CXCL13 serves a key role in inflammatory diseases. In previous studies, CXCL13 was observed as being expressed in patients with breast cancer and was associated with cancer metastasis (8-10). Furthermore, it has been reported that CXCL13 was particularly highly expressed in early breast cancer and was closely associated with prognostic factors such as lymph node positivity (11). These results indicate that high CXCL13 expression is an adverse factor for patients with breast cancer.

The biological effects of chemokine activity are mediated by interactions with $\mathrm{G}$ protein-coupled receptors $(12,13)$. CXCR5 is the primary receptor forCXCL13 and is expressed on a subset of T cells, and on all B cells in the blood, cerebrospinal fluid and lymphatic tissue (14). The interaction between CXCR5 and CXCL13 promotes the expression of integrin and the entrance of $\mathrm{T}$ cells into the lymph nodes. Therefore, CXCR5-deficient mice have severely impaired immune systems $(15,16)$. It has been suggested (17) that when anti-CXCR5 or-CXCL13 antibodies are injected into the original site of breast cancer, they can effectively block the chemotaxis of cancer cells, and that the expression of CXCR5 is upregulated in this cancerous tissue compared with normal breast tissue. A similar effect was observed in the lymph nodes (the most common site of breast cancer metastasis), where CXCL13 was upregulated (8); however, it was minimally expressed in unassociated tissues, such as skeletal muscle or brain tissue. Thus, cellular cluster formation and compartmentalization may be organized through CXCR5/CXCL13 interactions in breast cancer cells. CXCL13 and its receptor may contribute to tumor formation, with therapeutic intervention to interrupt CXCL13/CXCR5 interactions potentially improving the clinical course of patients with breast cancer. 
The mitogen-activated protein kinase (MAPK) signaling pathway is downstream of estrogen receptor activation and has been associated with breast cancer $(18,19)$. Extracellular-regulated protein kinases (ERK), including ERK1 and ERK2, are essential to cell proliferation and differentiation, and promote gene transcription and expression $(20,21)$. It has also been reported that ERK1/2 are activated by growth factors, and their continuous activation promotes cellular proliferation and malignant cell transformation (22). Downregulation of phosphorylated (p)-ERK1/2 attenuated cell growth and gene transcription. Recent research has associated CXCL13/CXCR5 expression with orofacial pain via ERK-mediated pro-inflammatory cytokines (23). The MAPK/ERK1/2 pathways have been previously investigated in the context of breast cancer (24). However, to the best of our knowledge, whether ERK signaling can be activated by CXCL13/CXCR5 expression in breast cancer has not been investigated. In the present study, the aim was to explore the signal transduction of the CXCR5/ERK pathway mediated by CXCL13 in breast cancer mice.

\section{Materials and methods}

Cells and animal models. A total of 30 adult BALB/c mice (female; 6 weeks old, 18-20 g) were purchased from the Vital River Laboratory Animal Technology Co.,Ltd. (Beijing, China). The animals were maintained in a 12-12 $\mathrm{h}$ light-dark cycle at a temperature of $22 \pm 1^{\circ} \mathrm{C}$ with free access to food and water in a specific pathogen-free environment. All animal procedures performed in the present study were reviewed and approved by the Animal Care and Use Committee of Yantaishan Hospital (Yantai, China). Three experimental groups were used to investigate the effect of CXCL13 in breast cancer: Control, Model (inoculated with $1 \times 10^{5} 4 \mathrm{~T} 1$ cells) and Inhibitor (inoculated with $4 \mathrm{mg} / \mathrm{kg}$ goat anti-mouse CXCL13 polyclonal antibody (cat no. SAB1408778; Sigma-Aldrich; Merck KGaA, Darmstadt, Germany) prior to being inoculated with $1 \times 10^{5} 4 \mathrm{~T} 1$ cells). A total of $15 \mathrm{BALB} / \mathrm{c}$ mice were randomly divided into these three groups, in which PBS and $1 \times 10^{5} 4$ T1cells were injected subcutaneously into the right hind leg of the Control mice and Model mice at days 6,12 and 18 respectively (day 0 was defined as the day they were grouped). The Inhibitor mice were perfused with $4 \mathrm{mg} / \mathrm{kg}$ goat anti-mouse CXCL13 polyclonal antibody at day $-2,-1$ and 0 , prior to undergoing the same injection program as the Model mice at days 6,12 and 18.

$4 \mathrm{~T} 1$ cells were obtained from female BALB/c mice breast cancer cell clones, which were purchased from the Type Culture Collection of the Chinese Academy of Sciences (Shanghai, China). Cells were cultured in Dulbecco's modified Eagle's medium (high glucose) (Beijing Solarbio Science \& Technology, Co., Ltd., Beijing, China) containing 10\% fetal bovine serum (Gibco; Thermo Fisher Scientific, Inc., Waltham, MA, USA), $1,000 \mu \mathrm{g} / \mathrm{ml}$ penicillin (Sigma-Aldrich; Merck $\mathrm{KGaA}$ ) and $100 \mu \mathrm{g} / \mathrm{ml}$ streptomycin (Sigma-Aldrich; Merck $\mathrm{KGaA}$, Darmstadt, Germany) at $37^{\circ} \mathrm{C}$ and $5 \% \mathrm{CO}_{2}$.

Measurement of tumor volume. The length (L) and width (W) of tumors were recorded every sixth day following treatment with $4 \mathrm{~T} 1$ cells. The tumor volume (V) was calculated using the formula $\left(\mathrm{V}=\mathrm{LxW}^{2} \mathrm{x} 0.52\right)$. At the age of 9 weeks, mice were anaesthetized by an intraperitoneal injection of Pentobarbibal (Jiangsu Hengrui Medicine Co., Ltd., Lianyungang, China) at a dose of $35 \mathrm{mg} / \mathrm{kg}$ under aseptic conditions, metastatic tumors were excised from the mice and frozen in liquid nitrogen.

Hematoxylin and eosin $(H \& E)$ staining. Tumor tissues were fixed in $4 \%$ paraformaldehyde at $4^{\circ} \mathrm{C}$ for $24 \mathrm{~h}$. The embedded tissue was then cut into sections $(5 \mu \mathrm{m})$. Subsequent to dewaxing with xylene, hydration was performed using a series of graded concentrations of ethanol (100\% ethanol for $5 \mathrm{~min}$, 95\% ethanol for $1 \mathrm{~min}, 80 \%$ ethanol for $5 \mathrm{~min}, 75 \%$ ethanol for $5 \mathrm{~min}$ and distilled water for $2 \mathrm{~min}$ ). H\&E staining was performed using the routine method at room temperature for $12 \mathrm{~min}$. Following dehydration, sections were treated with xylene at room temperature for $10 \mathrm{~min}$ twice. Then tissue sections were sealed with neutral resin and observed using a light microscope (magnification, x100) to check for histopathological changes.

Reverse transcription-quantitative polymerase chain reaction $(R T-q P C R)$. The total RNA of the breast cancer cells from the breast cancer tissue was extracted using TRIzol ${ }^{\circledR}$ (Takara Bio, Inc., Otsu, Japan). The purity of RNA samples was assessed using ultraviolet spectrophotometry and those with a 260/280 nm ratio of 1.8-2.0 were used for reverse transcription. The volume of RNA and buffer used were 2 and $98 \mu \mathrm{l}$, respectively.

Total RNA $(1 \mu \mathrm{g})$ was reverse transcribed using a reverse transcription kit (cat no. DRR047A; Takara Bio, Inc.) according to the manufacturer's protocol. RT-qPCR was performed using a Real-Time Detection system (Applied Biosystems; Thermo Fisher Scientific, Inc.) by SYBR Green I dye detection (Takara Bio, Inc.). The primers used in this study are included in Table I.

PCR amplifications were performed at $95^{\circ} \mathrm{C}$ for $3 \mathrm{~min}$, followed by 30 cycles at $95^{\circ} \mathrm{C}$ for $1 \mathrm{~min}, 56^{\circ} \mathrm{C}$ for $40 \mathrm{sec}$ and $72^{\circ} \mathrm{C}$ for $1 \mathrm{~min}$. $\beta$-actin was used as an endogenous control to normalize differences. Melting curves were created to ensure that the production of non-specific products was avoided. Quantification was performed by normalizing the cycle threshold values to those of $\beta$-actin and analyzing results using the $2^{-\Delta \Delta C \mathrm{q}}$ method (25).

Western blot. Total protein was extracted by using the Tissue Total Protein Lysis buffer (Sangon Biotech CO.,Ltd., Shanghai, China) according to the manufacturer's protocol. The protein samples were incubated at $0^{\circ} \mathrm{C}$ for $30 \mathrm{~min}$, and then centrifuged at $10,000 \mathrm{x} \mathrm{g}$ at $4^{\circ} \mathrm{C}$ for $8 \mathrm{~min}$, and supernatants were then extracted. Protein concentrations were quantified using a BCA Protein Assay Reagent kit (Pierce; Thermo Fisher Scientific Inc.). Protein samples $(40 \mu \mathrm{g})$ were separated via $10 \%$ SDS-PAGE and transferred to a polyvinylidene fluoride membrane. The membrane was blocked with 5\% skimmed milk for $1 \mathrm{~h}$ at room temperature, prior to an overnight incubation at $4^{\circ} \mathrm{C}$ with rabbit anti-mouse CXCL13 polyclonal antibody (dilution, 1:500; cat no. orb101825; Biorbyt Ltd., Cambridge, UK), rabbit anti-mouse CXCR5 monoclonal antibody (dilution, 1:500; cat no. orb5925; Biorbyt Ltd.), rabbit anti-p-ERK polyclonal antibody (dilution, 1:500; cat no. orb1733; Biorbyt Ltd.), rabbit anti-ERK polyclonal antibody (dilution, 1:500; 
Table I. Primer sequences.

\begin{tabular}{|c|c|}
\hline Genes & Sequences \\
\hline CXCL13 & $\begin{array}{l}\text { Forward, 5'-GAGGCAGATGGAACTTGAGC-3' } \\
\text { Reverse, 5'-CTGGGGATCTTCGAATGCTA-3' }\end{array}$ \\
\hline CXCR5 & $\begin{array}{l}\text { Forward, 5'-AACTACCCGCTAACGCTGGAAA } \\
\text { TGGAC-3' } \\
\text { Reverse, 5'-CACGGCAAAGGGCAAGAGAAG } \\
\text { ACC-3' }\end{array}$ \\
\hline ERK & $\begin{array}{l}\text { Forward,5'-TACACGCAGTTGCAGTACATCG-3 } \\
\text { Reverse,5'-CGCAGGATCTGGTAGAGGAAGT-3 }\end{array}$ \\
\hline$\beta$-actin & $\begin{array}{l}\text { Forward, 5'-TTGTTACCAACTGGGACG-3' } \\
\text { Reverse, 5'-GGCATAGAGGTCTTTACGG-3' }\end{array}$ \\
\hline
\end{tabular}

CXCL13, C-X-C motif chemokine ligand 13; CXCR5, C-X-C motif chemokine receptor 5; ERK, extracellular signaling-related kinase.

cat no. orb224458; Biorbyt Ltd.) and rabbit anti- $\beta$-actin polyclonal antibody (dilution, 1:500; cat no. orb 129534; Biorbyt Ltd.). The membrane was then washed 3 times for 5 min with TBST (TBS with $1 \mathrm{ml} / 1$ Tween-20). Finally, the membrane was incubated with horseradish peroxidase-conjugated secondary antibodies (dilution, 1:5,000; cat no. orb345943; Biorbyt Ltd.) for $2 \mathrm{~h}$ at room temperature, and then washed 3 times for 10 min with TBST. Imaging was performed using enhanced chemiluminescence (ECL) Prime Western Blotting Detection reagent (GE Healthcare, Chicago, IL, USA) in a dark room. The expression of the protein samples was standardized to $\beta$-actin, then band densities were scanned and quantified by the Image J 2.1 software (National Institutes of Health, Bethesda, MD, USA). The formula used to calculate the $\mathrm{p}-\mathrm{ERK} / \mathrm{ERK}$ ratio was as follows: $\mathrm{P}-\mathrm{ERK} / \mathrm{ERK}=(\mathrm{p}-\mathrm{ERK} / \beta$-actin $) /(\mathrm{ERK} / \beta$-actin $)$.

ELISA. The normal breast tissues and breast cancer tissues were mixed with $10 \mathrm{X}$ Tris- $\mathrm{HCl}$ buffer (cat no. ab128986; Abcam, Cambridge, UK), vortexed and centrifuged for $20 \mathrm{~min}$ at $1,000 \mathrm{x} \mathrm{g}$ at $4^{\circ} \mathrm{C}$. The obtained protein samples were quantified using ultraviolet spectrophotometry and adjusted to $1 \mu \mathrm{g} / \mu \mathrm{l}$. The concentrations of IL-1 $\beta$ (cat no. EK0394), TNF- $\alpha$ (cat no. EK0537) and tumor growth factor- $\beta 1$ (TGF- $\beta 1$ ) (cat no. EK0515) were detected using ELISA kits, according to the manufacturer's protocol (Boster Biological Technology, Pleasanton, CA, USA). The optical density (450 nm) was read using a microplate reader and the cytokine concentrations were calculated using a standard curve.

Statistical analysis. Results are expressed as the mean \pm standard deviation. Statistical analysis was performed using SPSS 19.0 (IBM Corp., Armonk, NY, USA). Differences between groups were compared by one-way analysis of variance, followed by Fisher's least significant difference test. $\mathrm{P}<0.05$ was considered to indicate a statistically significant difference.

\section{Results}

CXCL13 inhibition reduces tumor volume. Tumor volume was examined in the Control, Model and Inhibitor groups, and

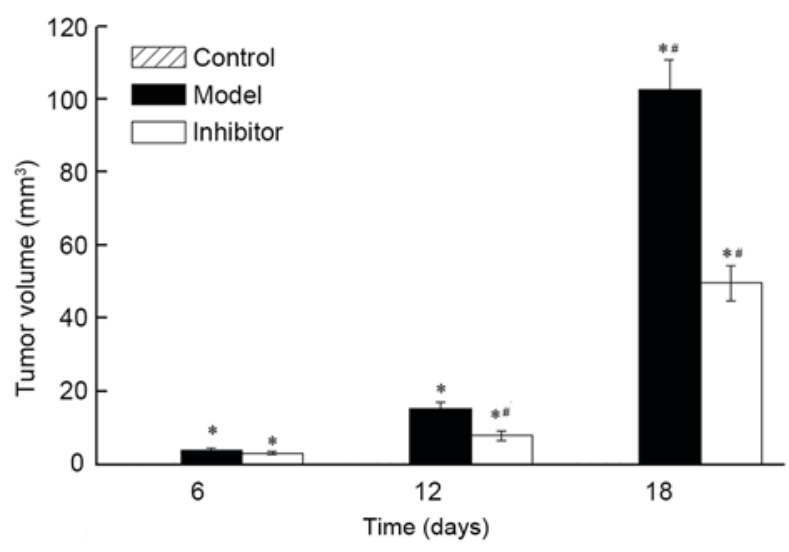

Figure 1. Effect of CXCL13 on tumor volume in Control, Model and Inhibitor group mice. Female BALB/c mice were randomly divided into three groups: Control; Model (inoculated with $1 \times 10^{5} 4 \mathrm{~T} 1$ cells); Inhibitor (inoculated with $4 \mathrm{mg} / \mathrm{kg}$ goat anti-mouse CXCL13 polyclonal antibody at day $-2,-1$ and 0 , then injected with $1 \times 10^{5} 4 \mathrm{~T} 1$ cells). The tumor volume of the three groups was calculated on days 6,12 and $18 .{ }^{*} \mathrm{P}<0.05$ vs. Control group; ${ }^{\#} \mathrm{P}<0.05$ vs. Model group. CXCL13, C-X-C motif chemokine ligand 13.

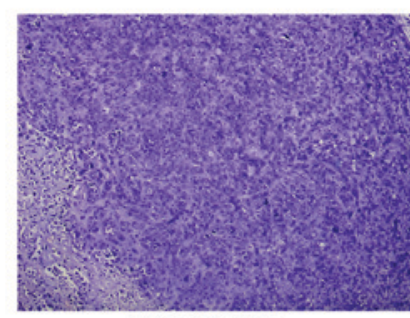

Model $(\times 100)$

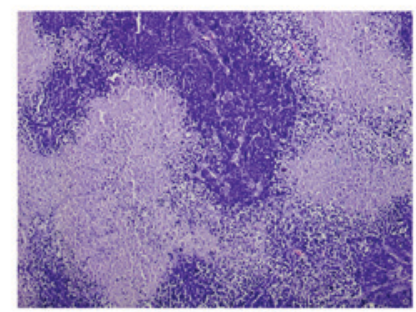

Inhibitor $(\times 100)$
Figure 2. Effects of CXCL13 on tumor morphology from H\&E staining in the Model and Inhibitor groups. After 9 weeks, all mice were sacrificed and the tumor tissues were sectioned and $\mathrm{H} \& \mathrm{E}$ stained for morphology observation. Images are of x100 magnification. CXCL13, C-X-C motif chemokine ligand 13; H\&E, hematoxylin and eosin staining.

no breast cancer characteristics were present in the Control group (Fig. 1). On days 6, 12 and 18, the tumor volume of the Model group was $3.77 \pm 0.68,15.31 \pm 1.62$ and $102.70 \pm 8.15 \mathrm{~mm}^{3}$, respectively. The tumor volume of the Inhibitor group on days 6,12 and 18 was $3.12 \pm 0.49,7.84 \pm 1.25$ and $49.63 \pm 4.74 \mathrm{~mm}^{3}$, respectively. The tumor volumes of the Model and Inhibitor groups were significantly larger than those of the Control group $(\mathrm{P}<0.05)$ The tumor volume of the Inhibitor group was significantly smaller compared with that of the Model group $(\mathrm{P}<0.05)$. These results indicate that the CXCL13 inhibitor significantly reduced the growth of breast cancer tumors.

Cellular apoptosis is induced by CXCL13 inhibition. The tumor cells in the Model group were densely distributed in a circumambient manner and arranged in a disordered fashion (Fig. 2). The cytoplasm was abundant and the nucleus-cytoplasmic ratio was imbalanced, cellular atypia was apparent and irregular mitosis was widespread. Damaged tumor cells in the Inhibitor group were surrounded with numerous lymphocytes and leukocytes and the growth of the tumor cells was inhibited. These results also support the hypothesis that CXCL13 inhibition inhibits the growth of the breast cancer tumors. 


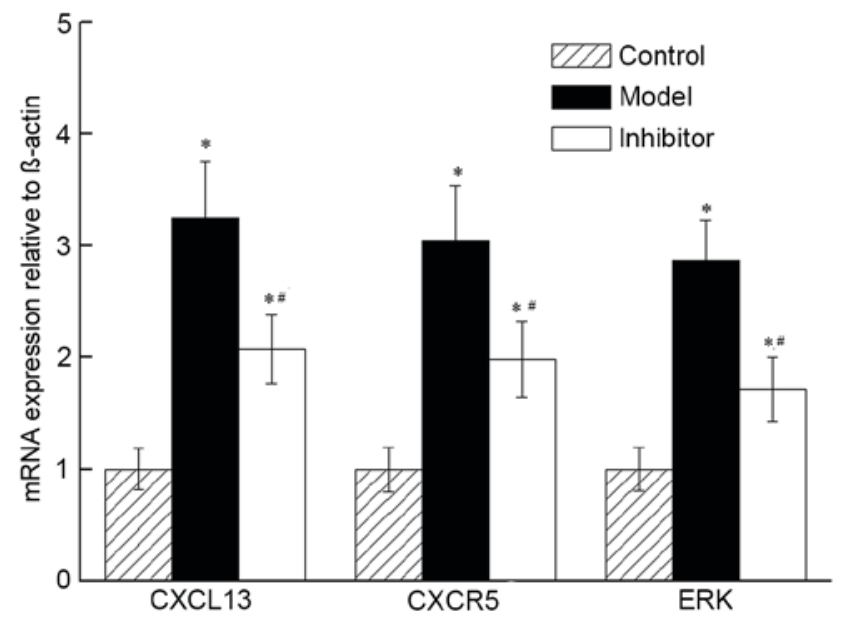

Figure 3. Effects of CXCL13 on the mRNA expression of 3 key genes of the CXCR5/ERK pathway (CXCL13, CXCR5 and ERK) in the Control, Model and Inhibitor groups. The relative mRNA expression was normalized to $\beta$-actin. "P<0.05 vs. Control group; ${ }^{*} \mathrm{P}<0.05$ vs. Model group. CXCL13, C-X-C motif chemokine ligand 13; CXCR5, C-X-C motif chemokine receptor 5; ERK, extracellular-regulated protein kinases; p-ERK, phosphorylated-ERK.

CXCL13 inhibition induces the expression of key genes of the CXCR5/ERK signaling pathway. The relative expression of CXCL13, CXCR5 and p-ERK mRNA in the Model group demonstrated fold changes of 3.24, 3.05 and 2.87 on days 6 , 12 and 18 , respectively, compared with the Control group. The inhibitor group demonstrated fold changes of 2.07, 1.98 and 1.71 on days 6,12 and 18 , respectively, compared with the Control group. The changes in the two groups represented a significant increase compared with the Control group ( $\mathrm{P}<0.05$; Fig. 3). The mRNA expression levels of CXCL13, CXCR5 and p-ERK in the Inhibitor group were significantly lower than those of the Model group $(\mathrm{P}<0.05)$. Together, the results indicated that the expression levels of mRNA in CXCL13, CXCR5 and p-ERK of the CXCR5/ERK pathway were reduced by treatment with the CXCL13 inhibitor.

CXCR13 inhibition induces the expression of key proteins of the CXCR5/ERK signaling pathway. There was no significant difference in total protein expression between each group. The protein levels of CXCL13, CXCR5 and p-ERK increased as the $\mathrm{p}$-ERK/ERK ratio increased in the Model and Inhibitor groups, compared with those in the Control group $(\mathrm{P}<0.05$; Fig. 4). The level of CXCL13, CXCR5 and p-ERK was low and the ratio of p-ERK/ERK was decreased in the Inhibitor group compared with in the Model group (ERK is activated by phosphorylation).

CXCL13 inhibition induces changes in cytokine concentration in breast tumor tissues. The concentrations of IL- $1 \beta$ and TNF in the Model and Inhibitor groups were significantly higher than those in the Control group. Following CXCL13 inhibition, tumor tissues exhibited fold-change increases in IL-1 $\beta$ and TNF of 8.20 and 4.51, respectively, in the Model group, and 3.80 and 2.53 , respectively, in the Inhibitor group $(\mathrm{P}<0.05)$, compared with the Control group (Fig. 5). The concentrations of IL-1 $\beta$ and TNF were significantly decreased $(\mathrm{P}<0.05)$ and that of TGF- $\beta 1$ was increased $(\mathrm{P}<0.05)$ in the

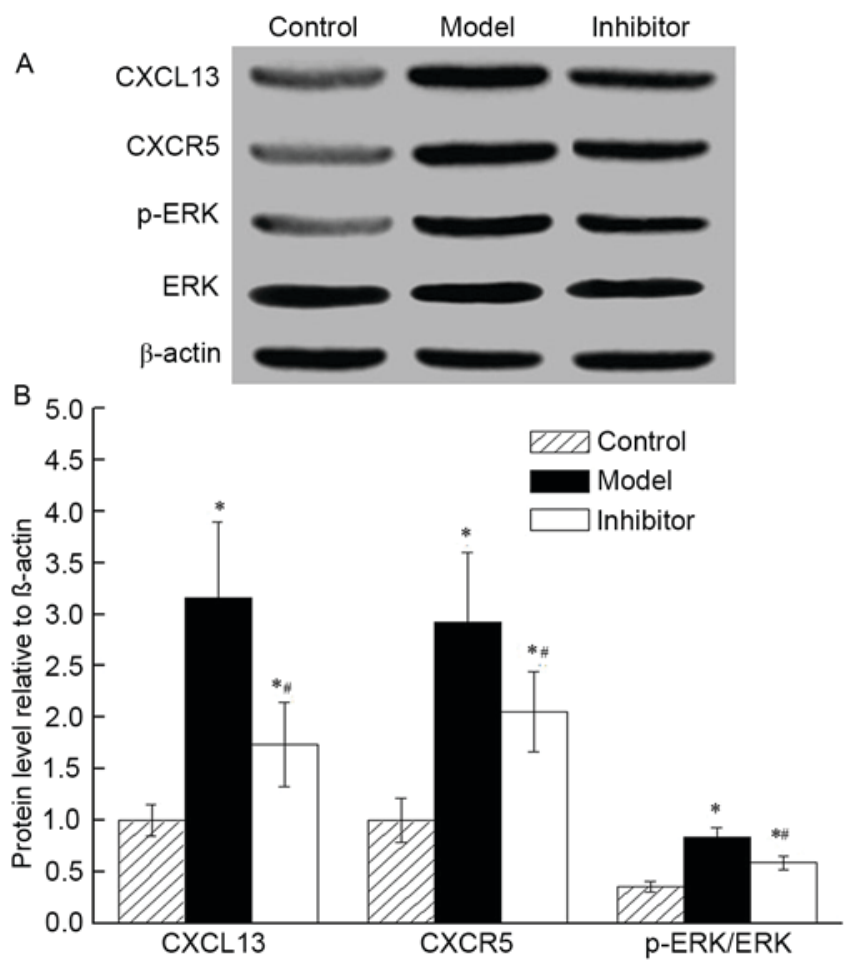

Figure 4. Effects of CXCL13 on the expression levels of three key proteins of the CXCR5/ERK pathway (CXCL13, CXCR5 and p-ERK) was analyzed in the Control, Model and Inhibitor groups. (A) Western blot analysis demonstrating that CXCL13, CXCR5 and p-ERK protein levels increased, with an increased p-ERK/ERK ratio, in the Model and Inhibitor groups compared with those in the Control group. The protein levels of CXCL13, CXCR5 and p-ERK decreased and the ratio of p-ERK/ERK decreased with CXCL13 inhibition. (B) Quantification of the western blot allowed for statistical analysis of the relative levels of proteins (normalized to $\beta$-actin). "P $<0.05$ vs. Control group; ${ }^{\prime} \mathrm{P}<0.05$ vs. Model group. CXCL13, C-X-C Motif Chemokine Ligand 13; CXCR5, C-X-C motif chemokine receptor 5; ERK, extracellular-regulated protein kinases; p-ERK, phosphorylated-ERK.

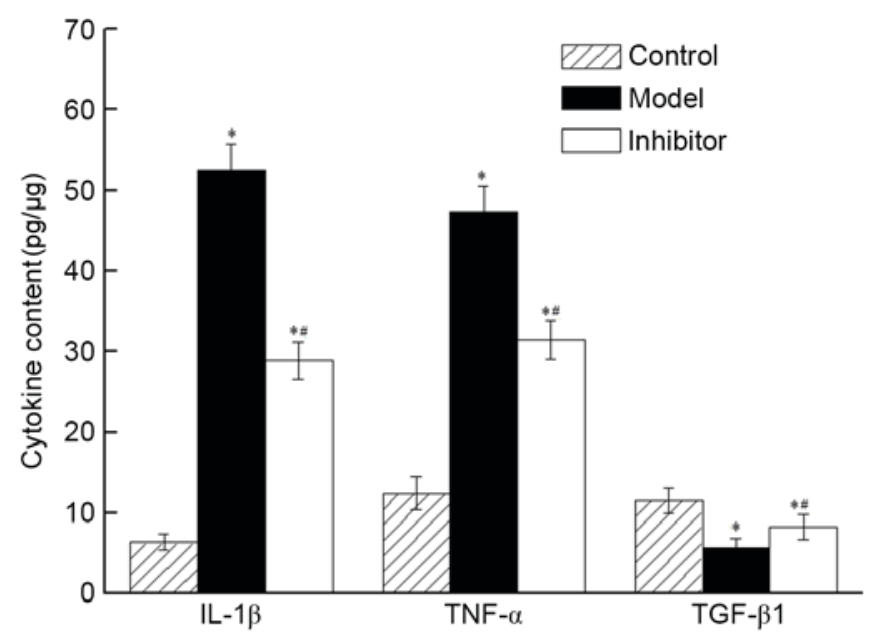

Figure 5. Effects of CXCL13 on the concentrations of three cytokines (IL-1 $\beta$, TNF and TGF- $\beta 1$ ) were analyzed by ELISA in the Control, Model and Inhibitor groups. ${ }^{~} \mathrm{P}<0.05$ vs. Control group; ${ }^{*} \mathrm{P}<0.05$ vs. Model group. CXCL13, C-X-C motif chemokine ligand 13; IL-1 $\beta$, interleukin-1 $\beta$; TNF, tumor necrosis factor; TGF- $\beta 1$, transforming growth factor $\beta 1$.

Inhibitor group, compared with those of the Model group. These results demonstrated that the CXCL13 inhibitor 
reduced the concentration of IL-1 $\beta$ and TNF and increased the concentration of TGF- $\beta 1$.

\section{Discussion}

Breast cancer is a disease that affects the physical and mental health of females worldwide, and attracts great attention from cancer researchers. The association between chemokines and breast cancer has been previously studied (26-28), and research has revealed that the expression of chemokines and their receptors serves a notable role in leukocyte maturation and internal tumor environment stabilization. The association between breast cancer and CXCR5/CXCL13 was first revealed in 2008; the marked overexpression of this chemokine indicated that CXCL13/CXCR5 interactions were involved in the initiation and/or progression of breast cancer (10). However, to the best of our knowledge, the present study is is the first to investigate the mediation oftheCXCR5/ERK signaling pathway by CXCL13 in breast cancer.

In the present study, it was demonstrated that the mean tumor volume of the Model mice was larger than that of the Control mice, whereas the mean tumor volume of the Inhibitor mice was smaller than that of the Model mice $(\mathrm{P}<0.05)$. This result indicated that the CXCL13 inhibitor could efficiently inhibit tumor growth. In agreement with previous research, these results indicated that CXCL13 expression was associated with breast cancer growth.

Cell apoptosis is an autonomic form of programmed cell death that is required to maintain homeostasis and is controlled by gene expression associated with the MAPK/ERK signaling pathway (29). In contrast to the Model group, cells of the Inhibitor group were surrounded by numerous lymphocytes and leukocytes. This indicates that CXCL13 inhibition facilitated cell apoptosis, and led to the generation of the hypothesis that cell apoptosis induced by CXCL13 inhibition is associated with the expression of MAPK/ERK signaling pathway gene/protein members.

The MAPK signaling pathway, which acts downstream of estrogen receptor activation, has been previously associated with the breast cancer $(18,19)$. The MAPK/ERK signaling pathway functions in various tissue types and is involved in the regulation of cellular proliferation and differentiation (30). The mRNA expression of the key genes in the CXCR5/ERK pathway, including CXCL13, CXCR5 and ERK, was attenuated in the Inhibitor group. Simultaneously, the levels of the CXCL13, CXCR5 and p-ERK proteins were decreased. From these data, it can be concluded that CXCL13 serves a notable role in mediating the CXCR5/ERK pathway. Furthermore, the ratio of p-ERK/ERK decreased, indicating that ERK was inhibited by phosphorylation.

IL-1 $\beta$ and TNF are important cytokines in regulating different transcriptional networks in primary $\beta$-cells (31). Soria et al (1) demonstrated that the inflammatory cytokines TNF and IL-1 $\beta$ were highly expressed in the tumors of patients with relapsed disease, and that these cytokines contributed to breast cancer development and metastasis. The results of the present study indicate that expression of CXCL13/CXCR5 promotes ERK activation and that CXCL13 inhibition decreases the concentrations of IL-1 $\beta$ and TNF, while increasing the level of TGF- $\beta 1$. IL- $1 \beta$ and TNF expression is activated downstream of the ERK signaling pathway. Together, these results suggest that the production of IL-1 $\beta$ and TNF as a result of CXCL13 inhibition is dependent on the ERK signaling pathway.

The present study demonstrated that CXCL13 was involved in promoting tumor growth and cell apoptosis. Although CXCL13 inhibition could not completely inhibit the growth of breast cancer tumors, CXCL13 served a key role in breast cancer progression via ERK-mediated production of inflammatory cytokines IL-1 $\beta$ and TNF.

Overall, the results of the present study revealed that the CXCR5/ERK pathway was mediated by CXCL13 in murine breast cancer. CXCL13 was also involved in promoting tumor growth and cell apoptosis, which were suppressed by the CXCL13 inhibitor. The results of the current study demonstrated that the mRNA and protein expression levels of CXCL13, CXCR5 and ERK were decreased in the Inhibitor group compared with in the Model group. Simultaneously, the ratio of $p-E R K / E R K$ and the concentrations of IL-1 $\beta$ and TNF were decreased, compared with the Model group. Therefore, the mechanism of action of CXCL13 in breast cancer progression may be associated with the CXCR5/ERK pathway, and the application of CXCL13 inhibitors may provide a novel therapeutic approach for the treatment of breast cancer.

\section{Acknowledgements}

Not applicable.

\section{Funding}

No funding was received.

\section{Availability of data and materials}

All data generated or analyzed during this study are included in this published article.

\section{Authors' contributions}

LX, ZL, SL and JM designed the study. LX, ZL and SL analyzed and interpreted the data. LX and JM wrote and revised the manuscript. All authors read and approved the final manuscript.

\section{Ethics approval and consent to participate}

All animal procedures performed in the present study were reviewed and approved by the Animal Care and Use Committee of Yantaishan Hospital (Yantai, China).

\section{Consent for publication}

Not applicable.

\section{Competing interests}

The authors declare that they have no competing interests. 


\section{References}

1. Soria G, Ofri-Shahak M, Haas I, Yaal-Hahoshen N, Leider-Trejo L, Leibovich-Rivkin T, Weitzenfeld P, Meshel T, Shabtai E, Gutman M and Ben-Baruch A: Inflammatory mediators in breast cancer: Coordinated expression of TNF- $\alpha$ \& IL-1 $\beta$ with CCL2 \& CCL5 and effects on epithelial-to-mesenchymal transition. BMC Cancer 11: 130, 2011.

2. Wang F, Li L, Chen Z, Zhu M and Gu Y: MicroRNA-214 acts as a potential oncogene in breast cancer by targeting the PTEN-PI3K/Akt signaling pathway. Int J Mol Med 37: 1421-1428, 2016.

3. Dauksa A, Jakstaitė A, Gasianec A and Dambrauskas Z: Loss of proapoptotic gene Apaf-1 expression in pancreatic cancer. Health Sci 25: 9-12, 2015

4. Li Y, Zheng Y, Li T, Wang Q, Qian J, Lu Y, Zhang M, Bi E, Yang M, Reu F, Yi Q and Cai Z: Chemokines CCL2, 3, 14 stimulate macrophage bone marrow homing, proliferation and polarization in multiple myeloma. Oncotarget 6: 24218-24229, 2015.

5. Tan KW, Evrard M, Tham M, Hong M, Huang C, Kato M, Prevost-Blondel A, Donnadieu E, Ng LG and Abastado JP: Tumor stroma and chemokines control T-cell migration into melanoma following Temozolomide treatment. Oncoimmunology 4 e978709, 2015.

6. Bryant VL and Slade CA: Chemokines, their receptors and human disease: The good, the bad and the itchy. Immunol Cell Biol 93: 364-371, 2015.

7. Li Y, Wang W, Tang L, He X, Yan X, Zhang X, Zhu Y, Sun J, Shi Y, Ma X, et al: Chemokine (C-X-C motif) ligand 13 promotes intrahepatic chemokine (C-X-C motif) receptor 5+ lymphocyte homing and aberrant $\mathrm{B}$-cell immune responses in primary biliary cirrhosis. Hepatology 61: 1998-2007, 2015.

8. Biswas S, Sengupta S, Roy Chowdhury S, Jana S, Mandal G, Mandal PK, Saha N, Malhotra V, Gupta A, Kuprash DV and Bhattacharyya A: CXCL13-CXCR5 co-expression regulates epithelial to mesenchymal transition of breast cancer cells during lymph node metastasis. Breast Cancer Res Treat 143: 265-276, 2014.

9. Chen L, Huang Z, Yao G, Lyu X, Li J, Hu X, Cai Y, Li W, Li X and Ye C: The expression of CXCL13 and its relation to unfavorable clinical characteristics in young breast cancer. J Transl Med 13: 168, 2015.

10. Panse J, Friedrichs K, Marx A, Hildebrandt Y, Luetkens T, Barrels K, Horn C, Stahl T, Cao Y, Milde-Langosch K, et al: Chemokine CXCL13 is overexpressed in the tumour tissue and in the peripheral blood of breast cancer patients. Br J Cancer 99: 930-938, 2008.

11. Chen L, Huang Z, Yao G, Lyu X, Li J, Hu X, Cai Y, Li W, Ye C and Li X: Erratum to: The expression of CXCL13 and its relation to unfavorable clinical characteristics in young breast cancer. J Transl Med 14: 318, 2016

12. Dorsam RT and Gutkind JS: G-protein-coupled receptors and cancer. Nat Rev Cancer 7: 79-94, 2007.

13. del Molino del Barrio I, Kirby J and Ali S: The role of chemokine and glycosaminoglycan interaction in chemokine-mediated migration in vitro and in vivo. Methods Enzymol 570: 309-333, 2016.

14. Meijer J, Zeelenberg IS, Sipos B and Roos E: The CXCR5 chemokine receptor is expressed by carcinoma cells and promotes growth of colon carcinoma in the liver. Cancer Res 66 : 9576-9582, 2006.
15. Zhu Z,Zhang X, Guo H, Fu L, Pan G and Sun Y: CXCL13-CXCR5 axis promotes the growth and invasion of colon cancer cells via PI3K/AKT pathway. Mol Cell Biochem 400: 287-295, 2015.

16. Wu W, Qian L, Chen X and Ding B: Prognostic significance of CXCL12, CXCR4 and CXCR7 in patients with breast cancer. Int J Clin Exp Pathol 8: 13217-13224, 2015.

17. Panse J, Friedrichs K, Marx A, Hildebrandt Y, Luetkens T, Bartels K, Horn C, Stahl T, Cao Y, Milde-Langosch K, et al: Chemokine CXCL13 is overexpressed in the tumour tissue and in the peripheral blood of breast cancer patients. Br J Cancer 99: 930-938, 2008.

18. Lobenhofer EK, Huper G, Iglehart JD and Marks JR: Inhibition of mitogen-activated protein kinase and phosphatidylinositol 3-kinase activity in MCF-7 cells prevents estrogen-induced mitogenesis. Cell Growth Differ 11: 99-110, 2000.

19. Bosch A, Li Z, Bergamaschi A, Ellis H, Toska E, Prat A, Tao JJ, Spratt DE, Viola-Villegas NT, Castel P, et al: PI3K inhibition results in enhanced estrogen receptor function and dependence in hormone receptor-positive breast cancer. Sci Transl Med 7: 283ra51, 2015.

20. Hindley A and Kolch W: Extracellular signal regulated kinase $($ ERK)/mitogen activated protein kinase (MAPK)-independent functions of Raf kinases. J Cell Sci 115: 1575-1581, 2002.

21. Tran DD, Koch A, Saran S, Armbrecht M, Ewald F, Koch M, Wahlicht T, Wirth D, Braun A, Nashan B, et al: Extracellular-signal regulated kinase (Erk1/2), mitogen-activated protein kinase-activated protein kinase 2 (MK2) and tristetraprolin (TTP) comprehensively regulate injury-induced immediate early gene (IEG) response in in vitro liver organ culture. Cell Signal 28: 438-447, 2016.

22. Liu S, Uppal H, Demaria M, Desprez PY, Campisi J and Kapahi P: Simvastatin suppresses breast cancer cell proliferation induced by senescent cells. Sci Rep 5: 17895, 2015.

23. Zhang Q, Cao DL, Zhang ZJ, Jiang BC and Gao YJ: Chemokine CXCL13 mediates orofacial neuropathic pain via CXCR5/ERK pathway in the trigeminal ganglion of mice. J Neuroinflammation 13: 183, 2016.

24. Milde-Langosch K, Bamberger AM, Rieck G, Grund D, Hemminger G, Müller V and Löning T: Expression and prognostic relevance of activated extracellular-regulated kinases (ERK1/2) in breast cancer. Br J Cancer 92: 2206-2215, 2005.

25. Livak KJ and Schmittgen TD: Analysis of relative gene expression data using real-time quantitative PCR and the 2(-Delta Delta C(T)) method. Methods 25: 402-408, 2001.

26. Soria $G$ and Benbaruch A: The inflammatory chemokines CCL2 and CCL5 in breast cancer. Cancer Lett 267: 271-285, 2008.

27. Aravindan BK, Prabhakar J, Somanathan T and Subhadra L: The role of chemokine receptor 4 and its ligand stromal cell derived factor 1 in breast cancer. Ann Transl Med 3: 23, 2015.

28. Kitamura T and Pollard JW: Therapeutic potential of chemokine signal inhibition for metastatic breast cancer. Pharmacol Res 100: 266-270, 2015.

29. Kudirka JC, Panupinthu N, Tesseyman MA, Dixon SJ and Bernier SM: P2Y nucleotide receptor signaling through MAPK/ERK is regulated by extracellular matrix: Involvement of beta3 integrins. J Cell Physiol 213: 54-64, 2007.

30. Zhang X, Ma L, Qi J, Shan H, Yu W and Gu Y: MAPK/ERK signaling pathway-induced hyper-O-GlcNAcylation enhances cancer malignancy. Mol Cell Biochem 410: 101-110, 2015.

31. Lepen Pleić I, Secombes CJ, Bird S and Mladineo I: Characterization of three pro-inflammatory cytokines, TNF $\alpha 1$, TNF $\alpha 2$ and IL-1 $\beta$, in cage-reared Atlantic bluefin tuna Thunnus thynnus. Fish Shellfish Immunol 36: 98-112, 2014. 